\title{
Collapse of Trust - Moulivakkam Twin Towers
}

S Radhakrishnan

PhD Research Scholar, Prist University. Thanjavur

Dr K G Selvan

Associate Dean, Prist School of Business, Prist University, Thanjavur

Dr S Senthil Kumar

Assistant Professor, Faculty of Management, SRM University, Kattankolathur, Kancheepuram Dist

\begin{abstract}
The rapid industrialization offering huge employment opportunities and the desire of people to move from rural to urban areas for living, necessitates construction of a number of dwelling apartments in the city.

Also, the easier availability of loan facilities for purchase of flats further boosted the construction industry.

Attracted by the sizeable profits coupled with free entry into this sector, innumerable people have got into construction industry now. People without any experience in construction and for that matter, not even with any background knowledge about it, are venturing into massive construction activities.

Many high rise buildings are being constructed by contractors who have no prior experience with multi storey buildings, said Confederation of Real Estate Developers' Association of India (CREDAI) President C Shekar Reddy [1].

Reputed builders set their own high standards and engage leading contractors to carry out construction activity, said N Nandakumar, President of Tamil Nadu Chapter of CREDAI. Some builders have quality in house construction wings. But some others, with a view to cutting costs, either engage small time contractors or put together a group of masons and labourers and carry out construction work on their own.

The Building Construction Authority of Singapore controls the entire gamut of government and private construction activity. They set high standards and any building that does not meet those standards is not given approval. They take responsibility and certify the quality of buildings that are supervised by them. On the contrary, in India, no regulatory agency and structural engineer is willing to take responsibility for the projects they are involved in" said Nandakumar [1]
\end{abstract}

\section{COMMON CAUSES FOR BUILDING COLLAPSE}

The most common causes attributed for building collapse are:

1. The foundations are too weak

2. The building materials are not strong enough - quality deficiency

3. Human errors

4. The load is heavier than expected \&

5. The strength is not tested

In our country, structure collapses and the alarming death toll are the most common sights.

\section{Statement I - Structure Collapses Incidents [2]}

\begin{tabular}{|l|l|}
\hline Year & No. of Incidents \\
\hline 2010 & 2677 \\
\hline 2011 & 3125 \\
\hline 2012 & 2764 \\
\hline 2013 & 3074 \\
\hline 2014 & 1833 \\
\hline
\end{tabular}


Statement II - Deaths due to Structure Collapses [2]

\begin{tabular}{|l|l|}
\hline Year & No. of Incidents \\
\hline 2010 & 2682 \\
\hline 2011 & 3161 \\
\hline 2012 & 2682 \\
\hline 2013 & 2832 \\
\hline 2014 & 1821 \\
\hline
\end{tabular}

\section{INTRODUCTION TO THE PROBLEM}

Constructing Multi Storeyed Buildings is always a difficult and testing one. More the number of floors, larger will be the risk factors associated with it. For constructing, especially, high rise buildings, the Builder is expected to have sound experience in construction field besides the knowledge of soil condition, quality of materials and basic civil engineering skills.

Even established companies with excellent track record, come across sudden problems during construction.

The case study on the 11 storey building collapse at Porur brings to light many shocking information, which are to be paid serious attention and call for appropriate action, at least for non recurrence of such things in future.

\section{OBJECTIVE OF THE STUDY}

This is the case study on the 11 storey building collapse at Moulivakkam, Porur. One building collapsed on its own during construction itself and the other building, semi built, was demolished by imploding. Could a thunder bolt cause such a devastation pulling down 11 storey building - the first one? Was that the actual cause at all for the collapse of the building?

The study revealed that the poor quality of construction and the negligence of soil condition are the prime causes of the collapse.

\section{LIMITATIONS OF THE STUDY}

As this is the case study of a particular sky scrapper structure collapsed, even during construction level itself, the revelation of this study could be an eye opener for other projects on the stringent procedures to be followed for safety of the building.

\section{Background of the Builder}

The details flash out by the builder in the electronic media speak pretty high of the builder. "head quartered in Madurai, Prime Sristi Housing Pvt Ltd's promoters have nearly two decades of extensive Real Estate Development experience. We at Prime Sristi believe our buildings should stand apart and should reflect engineering marvel. It is our intention that the quality of our products and services ..... [3]

Whereas the actual thing seems to be totally different.

"According to Police, Manoharan (builder), a native of Madurai, worked as a clerk with the Indian Bank in Madurai before opting for voluntary retirement in 2011. Post retirement, he turned a full time real estate dealer and graduated to a well known builder in a short time. Two of his engineers are also natives of Madurai and their professional authenticity is being verified" said Senior Police Officer.

Meanwhile, a release from the Council of Architecture, New Delhi, signed by the Registrar, has stated that Vijay Bargotra, the 11 storey building's prime architect, who was arrested along with Manoharan, was not registered with them. As per sections 2 (a), 35, 36 and 37 of the Architects Act, 1972, only a person registered as an architect with the Council can call himself as an Architect or function as one in India. (additional reporting by Sunitha Sekar) [4]

While their website makes a loud claim of two decades of extensive experience, the fact is falsifying their tall claim.

\section{Trust Heights Porur}

Trust Heights is a living space created through twin eleven storeyed apartment blocks situated on Kundrathur road near Porur junction. Tower "The Faith" has four apartments of 2 bhk and Tower "The Belief" has four apartments of 3 bhk in each floor. 
Price Range -51.2 Lakhs -84 Lac

2 to 3 BHK (975 - 1600 sqft)

Possession: Ready to Move

Price/sq ft: Rs. 5,250/-

Last updated : 02/06/2014 [5]

\section{Essential Things to be Taken into Account for High Rise Construction}

It is expected that the high rise builders must have certain basic knowledge and experience in such high rise building construction, as, it is totally different from the normal construction. He is also expected to construct exactly as per planning approval without any deviation. The essential points as commonly prescribed for such high rise constructions are as follows:

- The construction should be exactly as per plan approved by the competent authority.

- Any deviation or alteration must be approved by the authorities who earlier studied the plan an accorded approval. No deviation, whatsoever, should be allowed contrary to the original plan approval.

- The building must incorporate all modern technological systems.

- Structural system should be as certified and cleared by Structural Engineers only. Any deviation will lead to serious consequences.

- Safety and Fire Fighting Equipments should be incorporated.

- The building must be constructed with fire resistant materials.

- All floors should be connected with elevators.

- The contractor is also expected to have and implemented value engineering in the materials and the system of construction.

What is the Reason for the Collapse?

While it was easily shifted to lightning and thunder that crashed the building, the actual study at the site clearly showed that it was not due to lightning and the poorness in construction in all aspects, only led to the collapse.

Before even applying for plan approval, the first and foremost activity to have been honestly done was site clearance for construction.

"whenever the dampness of a site or the nature of the soil renders such precautions necessary, the ground surface of the site between the walls of any building erected thereon shall be rendered damp proof to the satisfaction of the authority. Any land passage or other area within the curtilage of a building shall be effectively drained by surface water drains or other means" [6]

Porur lake is only at a stone throw distance from the collapsed building. Previous incidents also proved that whenever the lake was full and overflowing, these areas were always inundated. Under such circumstances, it is a common question that would cross everyone's mind is that how the permission was obtained at such a risky site totally unsuitable for high rise buildings?

One more point is that the quality of materials used in the construction was not good and also the procedures for construction of such tall buildings were not adhered to.

The National Building Code of India Part 6 - structural design - section 4 Masonry imposes so many fine clauses on Materials, Mix proportions and strength of Mortars for Masonry, minimum thickness of basement walls, effective height of walls etc.,

How all these things were just ignored in such a high rise construction is really a bizarre one.

\section{Tale of a Doomed Project}

June 2013 CMDA issued planning permission to Prime Sristi Housing Pvt Ltd. Builder plans to construct 82 houses in two 11 storey blocks in Moulivakkam Village Panchayat. 
June 28, 2014 Tower B, crumbles after a heavy downpour, killing 61 construction workers from Tamil Nadu, Andhra and Odisha.

July 3, 2014 State Government constitutes a one man inquiry commission headed by Justice (retd) R Reghupathy.

August 2015 Commission's report is tabled in the Assembly. The report holds six persons responsible for the collapse. It suggests that a special unit be established to deal with the "hidden and underground transactions" between officials concerned at various levels and realtors/promoters

October 2015 Kancheepuram Collector orders demolition of the second tower. Builder approaches High Court seeking a stay.

December 2015 Madras High Court stays demolition

May 2016 Supreme Court upholds District Collector's orders to demolish second tower of the complex.

November 2, 2016 The second tower is brought down using implosion. The tower is razed to the ground in three seconds at $6.50 \mathrm{pm}$ after a daylong preparatory process. [7]

The 2014 Moulivakkam Building Collapse (Source: architexturez.net)

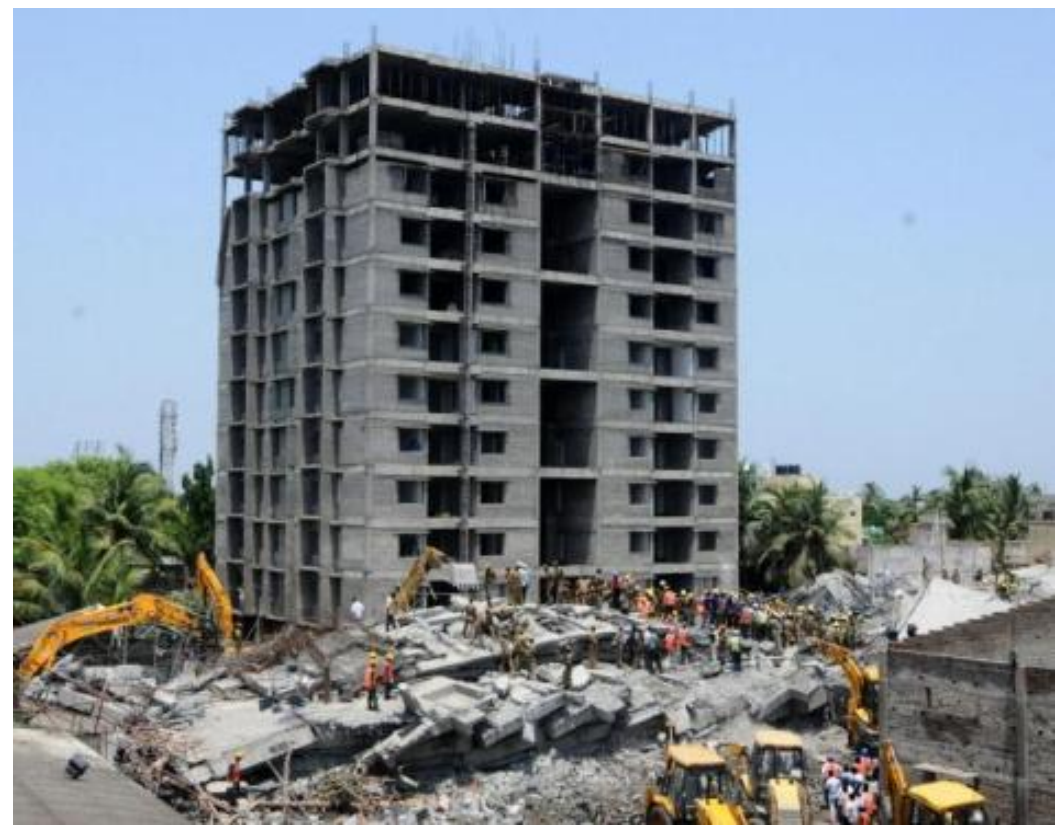

Second Building before Implosion



Second Building in Rubbles after Implosion 


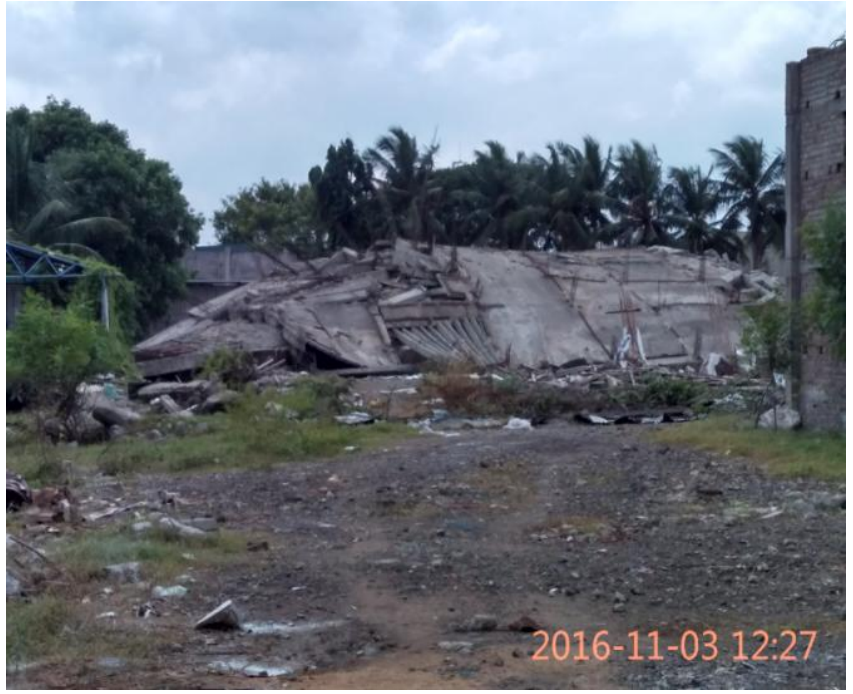

Weak Links in the Building Process

Experts say that the lack of geotechnical investigation and a focus only on deadlines are major reasons for building collapses. According to Aswath M U, Professor and Head, Department of Civil Engineering, Bangalore institute of Technology "developers reduce the time taken for construction for reduction in cost”.

The methods adopted by developers, design engineers, architects and construction agencies has only "time" for consideration.

There is seldom any analytical review or modification that is in effect. If concrete as a material is constructions friendly that tolerates abuses to a large extent, comprehensive understanding of the concrete mix for various purposes is taken up in the most disorganized fashion.

From the selection of the basic materials for the mix, the gradation required, the mixing, transporting, placement to curing and protection of concrete under extreme conditions of temperatures and high wind conditions, concrete cannot be expected to cover up deficiencies. The whole process has to be perfect, he says.

Geotechnical investigation and foundation engineering is perhaps, the weakest of the links. If adequate geotechnical engineering is not carried out by competent professionals, as envisaged in the various codes of practices, the load carrying capacity of the strata below cannot be estimated correctly. [8]

It is worthwhile to note about the compressive strength the concrete gains in various days.

Table No.3.Concrete strength [9]

\begin{tabular}{|l|l|}
\hline No. of days & $\%$ of strength \\
\hline 1 day & $16 \%$ \\
\hline 3 days & $40 \%$ \\
\hline 7 days & $65 \%$ \\
\hline 14 days & $90 \%$ \\
\hline 28 & $99 \%$ \\
\hline
\end{tabular}

From the above table, it is seen that the concrete gains $16 \%$ strength in one day, $40 \%$ in 3 days, $65 \%$ in 7 days, $90 \%$ in 14 days and $99 \%$ strength in 28 days. It is clear that concrete gains its strength rapidly in the initial days after casting, ie, $90 \%$ in just 14 days. When its strength has reached $99 \%$ in 28 days, still concrete continues to gain strength after that period, but that rate of gain in compressive strength is very less compared to that in 28 days.

After 14 days of casting concrete, concrete gains only $9 \%$ in next 14 days. So, rate of gain of strength decreases. We have no clear idea up to when the concrete gains the strength, 1 year or 2 years but it is assumed that concrete may gain its final strength after an year.

As the concrete strength is $99 \%$ at 28 days, it is almost close to its final strength, we rely upon the results of compressive strength test after 28 days and use this strength as the base of our design and evaluation. [9] 


\section{Gross Violations only Caused the Collapse}

From the charge sheet filed by (1) The State rep. by Inspector of Police, Mangadu Police Station, (2) The Additional Dy Commissioner of Police, Vepery and (3) The District Collector and District Magistrate, Kancheepuram - Respondents against the Builder (Petitioner), following critical information emerge.

- The structural plan was drawn by an Architect Tmt. Suganya, and structurally designed by S Nagesh, the Structural Engineer and submitted for approval by A1 Company through A8 Balaguruswamy and the plan approved by CMDA has not been used for the actual construction of 11 storeyed building and had it been used, the possibility of collapse would have been averted.

- The structural design given for the foundation, ie, the raft and pile were inadequate to bear the entire weight of basement + stilt +11 storeyed building.

- The collapse of the building is primarily attributable to gross deficiency in the structural design of the reinforced concrete columns, in gross violation of the requirements for structural design prescribed in the National Building Code of India.

- The columns designed are also inadequate to bear the dead weight of such heavy structure.

- The foundation was not designed as per the nature of the soil at the SOC and the foundation executed by the accused concerned are highly inadequate for the stable construction of eleven storeyed building.

- The improper detailing, such as provision of anchorage, length to reinforcement and column title are inadequate to cover the reinforcement.

- The design and construction of the building in all aspects are in violation of National Building Code, Bureau of Indian Standard.

- The materials such as concrete, steel and bricks used for the construction were not properly tested ad hence, the requirement level of concrete and tolerance limit of steel were not proper and

- The accused concerned, removed many columns in the CMDA approved plan at the basement level for the convenience to create more space for car parking knowledge to endanger the structure of the building

Before getting into the details of violations taken place during construction, it is quite pertinent that right from soil to bricks, everything is required to be thoroughly tested and only the materials that pass through the stringent tests are to be used for construction.

\section{Bricks Tests}

There are so many tests prescribed for testing the soundness of bricks for construction purposes.

Very important of the tests are as cited below.

Absorption Test: Immerse the brick in water for one full day. Measure the weight of the brick before immersion. After a full day, see the weight again. For a good quality brick, the amount of water absorption should not exceed $20 \%$ of weight of dry brick.

Hardness Test: A good brick should resist scratches against sharp things. So, for this test, a sharp tool or finger nail is used to make scratch on brick. If there is no scratch impression on brick, then it is said to be hard brick.

Soundness Test: This shows the nature of bricks against sudden impact. In this test, 2 bricks are chosen randomly and struck with one another. Then sound produced should be clear bell ringing sound and brick should not break. Then, it is said to be good brick.

Efflorescence Test: To know the presence of soluble salts in a brick, place it in a water bath for 24 hours and dry it in shade. After drying, observe the brick surface thoroughly. If there is any white or grey colour deposits, then it contains soluble salts and not useful for construction. [10] 


\section{Soil Tests:}

Soil test helps to determine varying physical and chemical characteristic of soil which can vary from place to place and from layer to layer even within the limits of the proposed structure. soil characteristics can change considerably within a small area. Weather, climatic changes, and site management can in the future affect the bearing qualities of the soil, if the foundation is not designed properly to the bearing capacity of the soil, then they will fail and so will be the building.

The soil investigation helps to determine the following: bearing capacity of the soil which determine the load sustenance capability of the soil, rate of settlement of the soil which affect the rate at which any structure placed on it settles, to select a type and depth of foundation, to select suitable construction technique, to predict and resolve probable foundation problems, to determine if the land can be subjected to subsidence and cause sinking of the building, to determine water table which affects humidity within the foundation and greatly affects the character of a soil which varies considerably with water content, mineral or chemical component of the soil that might affect the choice of construction materials.

For example, if the soil found to contain sulphur, it can attack the foundation, therefore sulphur resisting cement must be used in the foundation in such soil. [11]

While all above the basic and important tests which are to be necessarily conducted, especially for high rise buildings, one doubts whether these were seriously taken note of at all, by the builder who belied the Faith and Belief.

The details made available by Dr Devadas Menon, Structural Engineering Division, Civil Engineering Department, IIT, Chennai “... Thus, as established through site observations and structural analysis and design calculations, in my opinion, the collapse of the building is primarily attributable to gross deficiency in the structural design of the reinforced concrete columns, in gross violation of the requirements for structural design prescribed in the National Building Code of India $\cdots$

The statement made by Dr Monsingh D Devadas, Professor and Chairman, Faculty of Architecture, Anna University, Chennai “ ..... the applicant should obtain EIA (Environment Impact Assessment) clearance from the competent authority before commencement of the construction and the same has to be produced at the time of completion certificate as a pre condition for approval (Prorur lake is very close as seen in the CMA Land use Plan for Moulivakkam).... However, as per the CMDA approval drawing, it is only $16 \mathrm{~m}$.

At the time of planning approval, the qualifying road width should be $18 \mathrm{~m}$. Therefore, the plans submitted to Local Body for building approval has to be verified. I have revealed above contents in my report submitted to the court. Further I state that in Annexure II and III (Form - B\&C) as enclosures of the drawings, it has been noticed the filled in forms are incomplete. In both the forms there is no endorsement or any entry made by the CMDA. As regard to approval plans, I have stated in the report that both public and fire escape staircase are grouped together and fire escape staircase exit is not direct to outside open space. Refuge should be provided for the building above $24 \mathrm{mtrs}$ as per National Building Code 2005. Fire escape staircase specification not shown ....."

From the statement of Dr M Muttharam, Assistant Professor, Department of Soil Mechanics and Foundation Engineering, Anna University, Chennai “.... The soil investigation was conducted thoroughly and analysed that the bearing capacity of the raft is inadequate and settlement computations showed a higher value and that the existing raft foundation is inadequate to carry the total load from the 11 storeyed building ....."

From the statement of Dr C Umarani, Associate Professor, Division of Structural Engineering, Anna University, Chennai “..... Thus, as established through site observations and structural analysis and design calculations, in my opinion, the collapse of the building is primarily attributable to gross deficiency in the structural design of the reinforced concrete columns, in gross violation of the requirements for structural design prescribed in the National Building Code of India..... I have answered finally that the possibility of damage of the building leading to complete collapse of this RC Building may not occur to Thunder Shower ....."

From the statement of Er. P K Sathyamurthy, Assistant Executive Engineer, Office of the Engineer in Chief (Building), PWD, Chepauk, Chennai “.... As per the foundation working detailing drawings furnished for collapsed building Block B, columns that were not positioned in line 
with the centre of columns and centre of the pile cap which shows more eccentricity as shown figure below. Instead, the columns were skewed to one side which results in instability of structural frame. My observation is that, for this particular case, the structural design has not been done taking care of this more eccentricity at base. On reviewing the structural working drawings available for Block B, and also based on the site observations, the sizes and reinforcement of the columns are not sufficient enough to resist the axial compressive forces calculated as per the procedures laid out in the design codes.

The global collapse of this building is initiated due to simultaneous collapse of a large number of RC columns in the basement floor.... Here, it is pertinent, to note that this building was not able to withstand its own self weight itself (dead load alone), ie, live load not yet applied. After moving debris, during site inspection, one of the critical columns the crushing of concrete and buckling of exposed steel bars at base has been physically seen and noticed that inadequate sizes of column and reinforcement provided during execution.

As far as foundation is concerned, it is observed that the thickness of raft and number of piles provided for foundation is not adequate enough.... Further, it is stated that considering the complexity of the project, the builder has neither gone for project management nor carefully selected/appointed Architects, Structural Engineers, Construction/Site Engineers and skilled workers considering their qualification, experience, and expertise in these fields before implementation of this project which is against the Provision under clause $4.1 \& 4.2$ of National Building Code which resulted in bad structural design, deficiencies in construction and combination of both ....."

Sd Pre delivery order passed in Crl. O.P. No. 32578 of 2014 24.04.2015 Pre delivery order passed in Crl. O.P. No. 32578 of 2014 To The Hon'ble Mr Justic R S Ramanathan Respectfully submitted by sd (P.A. to R.S.R.J) [12]

\section{Revelations of Regupathy Commission}

The Government has appointed Justice $\mathrm{R}$ Regupathy Commission to inquire into the circumstances that led to the collapse of the building.

The commission suggested comprehensive legislation or vitalization of the existing legislation so that the essential features like insurance package creating triangular responsibilities among bank, builder and customer could be made.

Introducing penal provisions, insisting upon the construction firms taking up mega projects to deposit a sizable sum in fixed deposit for 10 years are the other measures recommended by the commission.

The commission also recommended reconstitution of the CMDA at the foundation level by forming a committee consisting of a technical officer of the agency, a law officer, experts in soil investigation, foundation design, structural engineering to compulsorily monitor all mega projects.

Apart from ensuring quality and compliance issues, the main task of the committee should be to inspect the site at all crucial stages, particularly during earth working for foundation, foundation concerting, laying the roof of basement floor and laying of the roof at each floor.

The commission also has made a strong case for constituting a Special Squad to check primarily all mega projects taking place in and around the City Limits so that recurrence of any bad incidents could be immediately stopped.

Justice Regupathy held six persons responsible for the collapse of the building, while pointing out that the incident was the best example about the dark side behind the real estate and construction business where money was considered to be the only ambition while lives of human beings/customers were put at stake.

The persons who have been held responsible for the collapse by the commission are Mr Manoharan, Managing Director of the Sristi Housing Private Ltd, M Muthukamatchi and M Balagurusamy, Directors, S Venkatasubramaniam, Structural Engineer, Vijay Bargotra, Consultant Architect and R Duraisingam, K Karthik and S Sankar Ramakrishnan Site Engineering.

The commission has also recommended constitution of a Committee so that the loss caused to the individuals who booked the flats and the injury and damage incurred by the neighbouring residents. Their buildings may be assessed and necessary recommendations may be made by such committee and compensation can be disbursed, the Judge said. [13] 


\section{CONCLUSION}

From all above, it is clearly evidenced that the right construction procedures were not followed for such high rise buildings. The tragedy highlights the network of illegal developers and a flyby night operators and a shortage of qualified architects and civil engineers.

The casual approach has led to all the problems.

The Materials right from bricks to sand were found to be not of proper quality, especially for such tall constructions.

The Soil test was not conducted in true sense. It is expected that for the plots, particularly near the lakes, soil test would be given prominent importance as the very foundation is involved. From the findings of the specialists mentioned above, one can only come to a conclusion that the soil testing was conducted, perhaps, not with its due importance, especially for such high rise constructions.

Structural testings also came under criticism. Apart from the fact that the structural testings were poor, it was also noticed that many alterations/deviations were observed in actual construction as compared to the drawings submitted to CMDA and the approved plan.

Some critical pillars were removed for enlargement of the car park.

Fire exits and fire safety equipments were not implemented.

The quality of concrete mix was not up to the mark. In addition to that, the normal full time of 28 days for the whole concrete to get solidified was also found to have been deviated in the construction.

The site engineers/incharge were not of the rightly qualified people for such construction.

The workmanship of people was also not up to the mark.

The hasty construction coupled with poor quality materials and people led to this deplorable collapse.

\section{RECOMMENDATIONS}

This collapse has shaken the whole nation.

The law should enforce all the builders to take construction related Insurance Policies. No builder should be permitted to even lay the foundation stone without insurance policies.

Builders should be asked to open an escrow account and deposit about $40-50 \%$ of money collected to take care of any eventualities.

Developers should make known to the public the original plan and approval thereof for the same, if any alternations/deviations made, details of such and also the approval details for the deviations etc., should be disclosed.

The Builders should also indicate the declared date of completion as at the beginning of the project, if any delays take place, the details of such delays should be made known to all the people who booked the flats.

If any delays take place without legitimate reason, the builders should pay penalty for such delays to the people who already booked the flats, for the delayed period.

No addition or deletion of the plan already approved should be permitted, even if it is sought for on specific cases, as such things will only lead to weakening of the whole construction.

The people who do not have the requisite qualification and experience should not be permitted to venture into construction business. If anybody is found to do so, they should be sternly dealt with.

The Site Engineer should be a qualified and experienced person.

Soil Test must be carried out by qualified engineers and a certificate confirming the fitness of soil for such construction, must be provided to all the prospective customers. Such a certificate should also be prominently kept at the construction site.

Similarly, Structural Engineer's certificate should also be obtained and copy given to prospective customers.

The approval for construction - be that CMDA or Local Body, should be accorded only after the soil test certificate and structural engineer's certificate are submitted along with the plan approval. 
The Approval Authority should also take up the responsibility of monitoring the constructions periodically, at least, the sites with more than 2 floors, to check and deter any unauthorised or deviated construction.

The builder should be made responsible for maintenance of the building for at least a period of three years. For anything untoward happening, the builder must be accounted for same.

Laws should also be enacted in such a way that for the people who booked the flats but never owned the same, their payments should be absorbed by the banks (such as uncollectable debts). This would, to some extent, mitigate the misery of the people.

Also, the builders who flouted the construction procedures or were responsible for collapse of the building must be debarred from business for a period of at least 10 years. This would impose self restraint on the builders.

\section{REFERENCE (WEB SOURCE)}

[1] No regulatory mechanism for contractors in India - Times of India).

[2] National Crime Records Bureau

[3] Prime Sristi Housing Pvt Ltd Real Estate Developer).

[4] From clerk to High Profile Builder in 3 years - The Hindu.

[5] Trust Heights Porur by Prime Sristi Housing Pvt Ltd in Chennai Central ....

[6] National Building Code of India 2005 - Point no. 6 Requirement of Plots; Clause 6.2 Damp sites and 6.3 Surface Water Drains"

[7] The Hindu Chennai Thursday dated $3^{\text {rd }}$ November 2016.

[8] Weak links in the building process. A Report by Ranjani Govind The Hindu dated 12/11/16

[9] The Constructor.pushengage.com

[10] (http://theconstructor.org/building/types-of-tests-on-bricks/12701/)

[11] Why soil investigation is necessary for your building project

[12] Manoharan Vs The State on $24^{\text {th }}$ April 2015 Indian Kanoon

[13] 2014 Chennai Building Collapse from Wikipedia, the free encyclopedia 